\title{
AVALIAÇÃO DE POLÍTICAS PÚBLICAS DE DESENVOLVIMENTO SUSTENTÁVEL: DILEMAS TEÓRICOS E PRAGMÁTICOS
}

\author{
Everkley Magno Freire Tavares
}

Mestre em Desenvolvimento e Meio Ambiente - PRODEMA/UERN, professor da Universidade Potiguar - UnP - Campus de Mossoró-RN e colaborador do CEFET-UNED. everkley@unp.br

Recebido em fevereiro de 2005 e Aceito em abril de 2005

\begin{abstract}
RESUMO
A discussão sobre o desenvolvimento sustentável tornou-se objeto de interesse público e acadêmico. Todavia existem dilemas na implementação de políticas públicas e avaliação de experiências sustentáveis no país. A proposta deste artigo é discutir alguns critérios de avaliação e sustentabilidade, tais como eficácia, eficiência, efetividade, prudência ecológica, eficiência econômica e justiça social. Para tanto, a revisão bibliográfica apoiouse em autores que tratam destes temas, entre eles destacamos: Arretche (1999), Cavalcanti (1995) e Sachs (1993). Para o êxito de uma política pública se faz necessário avaliar estes critérios para mensurar os custos/benefícios e os impactos desejados.
\end{abstract}

Palavras-chave: avaliação, políticas públicas, desenvolvimento sustentável, efetividade.

\section{PUBLIC POLITICS OF SUSTAINABLE DEVELOPMENT AVALIATION: THEORETHICAL AND PRAGMATIC DILEMMA}

\begin{abstract}
The subject on the sustainable development became a theme of public and academic interest. However, there are problems in the implementation of public politics and evaluation of sustainable experiences in Brazil. The proposal of this paper is to argue some criteria of evaluation and sustainable development such as, efficacy, efficiency, effectiveness, ecological prudence, economic efficiency and social justice. So, the bibliographical revision was supported in authors who deal with those subjects. Among them, it is mentioned Arretche (1999), Cavalcanti (1995) and Sachs (1993). For a public politic success it is necessary to evaluate those criteria to measure the cost/benefits and the desired impacts.
\end{abstract}

Key Words: Public evaluation, Politics, Sustainable development, Effectiveness. 


\section{AVALIAÇÃO DE POLÍTICAS PÚBLICAS DE DESENVOLVIMENTO SUSTENTÁVEL: DILEMAS TEÓRICOS E PRAGMÁTICOS}

\section{INTRODUÇÃO}

A discussão sobre o desenvolvimento sustentável tem estado presente em diversos setores da sociedade, sendo objeto de estudos, reflexões e debates presentes tanto no âmbito acadêmico, como nos movimentos sociais, ONGs e mídia.

A idéia de desenvolvimento sustentável tem sido construída a partir de distintas perspectivas, em contraponto à visão tradicional de desenvolvimento herdada do século XIX, que privilegia o crescimento econômico e a industrialização como sinônimos de desenvolvimento, desconsiderando o caráter finito dos recursos naturais.

Nesse sentido, o desenvolvimento sustentável resgata as premissas de eqüidade social, responsabilidade ecológica e a participação cidadã como partes indissociáveis do desenvolvimento. Nessa perspectiva, a participação cidadã é uma possibilidade para a gestão das políticas públicas direcionadas ao desenvolvimento economicamente viável, socialmente justo e ecologicamente equilibrado.

Um consenso bastante propagado nos últimos anos é o da necessidade de metodologias pragmáticas capazes de avaliar o impacto social dessas novas orientações sobre o modelo de desenvolvimento convencionado e que vem sendo adotado nas últimas décadas, pois as discussões são muitas, todavia existem grandes dilemas no aspecto de avaliar os resultados das experiências realizadas até agora nos países, regiões e municípios. Existe uma grande distância entre o discurso propagado acerca do desenvolvimento sustentável que vem acontecendo mais significativamente a partir da publicação do Relatório Brundtland em 1987 e reforçado pelos inúmeros tratados e convenções das Nações Unidas e, a forma de implementação dessas resoluções.

O presente artigo discute, em primeira instância, o processo de construção da noção de desenvolvimento sustentável, apontando assim, os princípios da sustentabilidade econômica, política, demográfica, geográfica, cultural e social necessários ao processo de gestão de políticas e programas.

Em seguida, aponta os critérios de avaliação eficácia, eficiência e efetividade de políticas necessários para apreender quais os resultados obtidos nos distintos momentos de sua constituição e implementação. Pois existem ainda muita dificuldade em estabelecer procedimentos metodológicos que apreendam os resultados das políticas públicas e que possibilitem dizer por que determinadas políticas foram, ou não, exitosas e por que chegaram, ou não a certos resultados.

\section{O que é uma sociedade sustentável?}

Para Acserald e Leroy (1999), o projeto de uma sociedade sustentável está na construção de uma sustentabilidade democrática no país, reivindicando e fazendo com que as camadas populares tornem-se sujeitos políticos de seu ambiente material, territorial, social, econômico e ambiental. A sociedade sustentável é aquela em que o desenvolvimento está integrado à natureza, com respeito à diversidade biológica e sócio-cultural, exercício 
responsável e conseqüente da cidadania, distribuição eqüitativa das riquezas e condições dignas de desenvolvimento.

A criação de oportunidades sociais contribui diretamente para a expansão das capacidades humanas e da qualidade de vida. A participação cidadã a fim de ser um processo de mobilização das energias sociais, dos recursos e das potencialidades locais para a implementação de mudanças que elevem as oportunidades sociais e as condições de vida no plano local (movimento endógeno), carece de articulação das condições objetivas e subjetivas do município para assumir a gestão das políticas públicas e a capacidade de gerenciamento dos municípios, através do executivo, ONGs e demais segmentos sociais com o controle social das políticas. E a recompensa disto vai além dos resultados da operação técnica legal na implementação das políticas públicas, influenciando, sobretudo, as habilidades produtivas e criativas das pessoas, da ação política e o crescimento econômico, através da prudência ecológica, eficiência econômica e justiça social (Sachs, 1993).

Assim, a idéia de sustentabilidade implica na premissa de que é preciso definir uma limitação nas possibilidades de crescimento e um conjunto de iniciativas que levem em conta a existência de interlocutores e atores sociais relevantes e ativos através de práticas educativas e de um processo de diálogo informado, o que reforça um sentimento de coresponsabilização e de constituição de valores éticos. Isso também implica, que uma sociedade sustentável não pode ignorar nem as dimensões culturais, nem as relações de poder existentes e muito menos, o reconhecimento das limitações ecológicas, sob pena de manter um padrão predatório de desenvolvimento, uma forma de governança centralista e autoritária (Jacobi, 1999).

A idéia de sustentabilidade foi pela primeira vez introduzida na discussão ambiental em 1987, no documento "Nosso Futuro Comum” ou relatório Brundtland ${ }^{1}$. Neste documento, a sustentabilidade é considerada a chave para a resolução de problemas ambientais, na medida em que fomenta estratégias qualitativas e quantitativas para modificar o processo de destruição em que a natureza se encontra. A Comissão Brundtland (1991, p. 22) definiu o desenvolvimento sustentável como um novo caminho de progresso social e econômico que: "(...) procura atender as aspirações do presente sem comprometer a possibilidade de atendê-las no futuro". A partir desse consenso global, devemos formular e implementar alternativas de gestão para superar os obstáculos a sustentabilidade do meio ambiente, superando a lógica tradicional de subjugar a natureza ao nosso bel prazer e a reduzida à situação de mera mercadoria para especulação a curto prazo, pois, na verdade, como sabemos, ela é uma condição indispensável e indissociável da existência e da sobrevivência humana e, os recursos são finitos.

A prudência ecológica significa poupar recursos naturais administrados com a preocupação de garantir a continuidade e a regularidade da atividade econômica e a qualidade do ambiente, condição para a qualidade de vida; eficiência econômica representa a capacidade de produzir mais e melhor com economia de recursos, capital e trabalho, particularmente; e justiça social significa oportunidades semelhantes para a população. A partir dessas atribuições, as diversas agendas públicas e acordos internacionais impulsionaram novas

\footnotetext{
${ }^{1}$ A Comissão Brundtland, presidida por Mansour Khalid e pela então primeira-ministra da Noruega Grõ Harlem Brundtland, da qual originou o nome do relatório, foi organizada pela ONU em 1983, para estudar a relação entre o desenvolvimento e o meio ambiente e criar uma nova perspectiva para abordar estas questões. O Relatório “Nosso Futuro Comum”, produzido pela Comissão sobre Meio Ambiente e o Desenvolvimento -UNCED, veio ao público em 1987.
} 
demandas e responsabilidades aos países em relação às suas estratégias políticas para o desenvolvimento.

Em linhas gerais, o projeto de uma sociedade sustentável aponta para uma justiça com eqüidade, distribuição das riquezas, eliminando as desigualdades sociais; para o fim da exploração dos seres humanos; para a eliminação das discriminações de gênero, raça, geração ou qualquer outra; para garantir a todos e a todas os direitos à vida e a felicidade, saúde, educação, moradia, cultura, emprego e a envelhecer com dignidade; para o fim da exclusão social, para a democracia plena. Estes novos princípios para uma sociedade sustentável entram em choque com os modelos tradicionais da sociedade. Vejamos o seguinte quadro:

\section{Quadro 01: Conjunto de princípios que regem as sociedades não sustentáveis e as sociedades sustentáveis}

\begin{tabular}{|l|l|}
\hline \multicolumn{1}{|c|}{ Sociedade Não Sustentável } & \multicolumn{1}{c|}{ Sociedade Sustentável } \\
\hline Domínio sobre a natureza. & Harmonia com a natureza. \\
\hline Meio ambiente como recurso. & $\begin{array}{l}\text { Natureza constituída por seres vivos com } \\
\text { direito à vida, independentemente do seu } \\
\text { valor de uso. }\end{array}$ \\
\hline Objetivos materiais/crescimento econômico & $\begin{array}{l}\text { Objetivos não materiais/sustentabilidade } \\
\text { ecológica. }\end{array}$ \\
\hline Recursos naturais ilimitados & Recursos finitos \\
\hline $\begin{array}{l}\text { Soluções baseadas exclusivamente na cada situação e } \\
\text { tecnologia avançada/consumismo }\end{array}$ & $\begin{array}{l}\text { Soluções adaptadas a cadada } \\
\text { ecossistema/satisfação das necessidades } \\
\text { básicas/reciclagem. }\end{array}$ \\
\hline Centralização/grande escala & Descentralização/pequena escala \\
\hline $\begin{array}{l}\text { Autoritarismo/estruturas } \\
\text { repressivas/desigualdade }\end{array}$ & $\begin{array}{l}\text { Estruturas democráticas/participação } \\
\text { social/igualdade. }\end{array}$ \\
\hline
\end{tabular}

Fonte: DIEGUES, A. C. (1992) citado por HELENA \& BICUDO (1994).

Estes princípios aliados à necessidade de um processo endógeno de mudança a partir do âmbito local é praticamente um consenso entre os que discutem o desenvolvimento sustentável. A proposta desse tipo de processo é de gerar inovações adequadas às necessidades específicas de cada lugar e, na mesma medida, dar respostas aos problemas globais da cidade, do município ou do espaço de vida local, tendo como parâmetros, princípios sustentáveis.

Essa mudança de atitudes, quando inseridas nas instituições políticas, possibilita uma transformação substancial nas relações políticas entre o Estado e as comunidades. $\mathrm{O}$ respeito à autonomia comunitária transforma os atores de objeto em sujeito do seu próprio desenvolvimento, conferindo, não apenas maior efetividade aos processos de gestão, mas, sobretudo, a tão desejada sustentabilidade, através do debate público entre as forças que se complementam e se contrapõem numa realidade vista como possível de ampliar o espaço democrático nas sociedades.

Considerando que uma das principais dificuldades num processo de sustentabilidade democrática está no confronto entre interesses privados e interesses públicos, vale a ressalva de que nem sempre o Estado ou uma associação civil representam os interesses públicos, garantindo melhores resultados. Isso significa, segundo Carvalho (1992, p.36 
apud Guimarães, 2001, p. 189), uma: “... inversão do espaço público, submetendo-o a interesses privados. Esse desinteresse pelo que é comum e público, beneficia a apropriação privada do que é, por direito, de todos, descaracterizando a esfera pública”.

Por riscos ambientais compreendem-se aqueles eventos, sejam naturais ou mesmo causados pelo homem (antrópicos), mas que põem em risco a saúde humana e os ecossistemas, produzindo efeitos que repercutem em escala global. Esses riscos que podem ser tanto originados em países desenvolvidos como nos países em desenvolvimento, podendo através dessa disseminação, causar efeitos globais.

Ignacy Sachs (1993, p. 11-55), prefere usar a expressão ecodesenvolvimento em lugar de desenvolvimento sustentável e identifica no modelo cinco dimensões de sustentabilidade de que, segundo ele, todo planejamento de desenvolvimento precisa levar em conta: 1) a sustentabilidade social, que se entende como criação de um processo de desenvolvimento que seja sustentado por um outro crescimento e subsidiado por uma outra visão do que seja uma sociedade boa. A meta é construir uma civilização com maior eqüidade na distribuição de renda e de bens, de modo a reduzir o abismo entre os padrões de vida dos ricos e dos pobres; 2) a sustentabilidade econômica, que deve ser tornada possível através da alocação e do gerenciamento mais eficiente dos recursos e de um fluxo constante de investimentos públicos e privados. Nessa dimensão, a eficiência econômica deve ser avaliada em termos macrossociais, sistêmicos na relação com as partes, e não apenas através do critério da rentabilidade empresarial de caráter macroeconômica; 3) a sustentabilidade ecológica, que pode ser melhorada se seguidos os seguintes princípios: ampliar a capacidade de renovação dos ciclos ecológicos da Terra, intensificando o uso do potencial de recursos dos diversos ecossistemas, com um mínimo de danos aos sistemas de sustentação da vida; limitar o consumo desordenado dos recursos naturais e respeito à biodiversidade ecológica; intensificar a pesquisa para a obtenção de tecnologias de baixo teor de resíduos e eficientes no uso de recursos para o desenvolvimento urbano, rural e industrial; definir formas de uma adequada proteção ambiental; 4) a sustentabilidade espacial, que deve ser dirigida para a obtenção de uma configuração rural-urbana mais equilibrada e uma melhor distribuição territorial dos assentamentos humanos e das atividades econômicas; e 5) sustentabilidade cultural, incluindo a procura de raízes endógenas de processos de modernização e de sistemas agrícolas integrados, processos que busquem mudanças dentro da continuidade cultural e que, traduzam o conceito normativo de ecodesenvolvimento como conjunto de soluções específicas para o ecossistema, a cultura e o espaço de vida local, respeitando a diversidade biológica e cultural.

O esforço que a comunidade internacional está desenvolvendo para alterar o rumo atual da degradação ambiental e as conseqüências sociais, através das conferências de cúpula da Organização das Nações Unidas - $\mathrm{ONU}^{2}$ serve para balizar as ações humanas no espaço de suas comunidades.

As discussões tornam-se cada vez mais freqüentes e abrangem várias temáticas como: as riquezas naturais; a poluição do ar, da água e do solo; o efeito estufa decorrente da agressão à camada de ozônio; o espaço urbano; o destino das florestas tropicais; a modernização agrícola, o crescimento da população; a biodiversidade; a qualidade de vida e organização política (Brüseke, 1995).

\footnotetext{
${ }^{2}$ Nas últimas décadas, a ONU realizou várias conferências, tais como: Infância, em Genebra (1990), Meio Ambiente e Desenvolvimento Humano, no Rio de Janeiro (1992); População e Desenvolvimento, no Cairo (1994); Pobreza e Desenvolvimento Social, em Compenhague (1995); Assentamentos Humanos Habitat II, em Istambul (1996) e tantas outras, estimulando o debate global acerca da questão ambiental. Na realidade é preciso uma mudança radical nas formas de relacionamento com os outros e o meio ambiente, pois se não agirmos responsavelmente, em breve teremos fracassado enquanto espécie.
} 
Além disso, a RIO 92 incorporou preocupações com a cooperação internacional para acelerar o desenvolvimento sustentável dos países em desenvolvimento e a implantação de políticas internas correlatas. Preocupações essas, com a pobreza, as mudanças nos padrões de consumo mundial, a difusão da relação entre o desenvolvimento sustentável e densidade demográfica e com a saúde humana, além da relação com o próprio meio ambiente. Foi um dos maiores eventos de discussões sobre o Desenvolvimento Sustentável, culminando no maior tratado sobre ambientalismo já assinado. Seus principais documentos foram a Agenda 21 e a Declaração do Rio.

A noção de desenvolvimento sustentável não é apenas uma nova forma de adjetivação, mas implica considerar e assumir novos padrões de competitividade e eqüidade, significando uma nova racionalidade pragmática de gestão, incluindo a incorporação no processo de desenvolvimento daquilo que é público e não somente estatal.

Isto quer dizer, que a gestão é acima de tudo, um conceito de como deve ser feita a administração de um sistema, de tal forma que fique assegurado um funcionamento adequado; o seu melhor rendimento, como também, sua perenidade e seu funcionamento. A gestão pressupõe uma utilização racional do potencial dos recursos naturais e humanos disponíveis, subutilizados ou simplesmente ignorados; bem como, a criação e adaptação de recursos tecnológicos, metodológicos e formas de organização social e política.

\section{Algumas palavras acerca da avaliação de políticas públicas e do desenvolvimento}

O consenso que se estabeleceu em torno da sustentabilidade democrática na gestão de políticas públicas, é o do envolvimento participativo dos diversos atores sociais e políticos que englobam a comunidade ou a sociedade civil local.

Assim, a capacidade da população de advogar por seus interesses é ingrediente chave ao processo de efetividade de políticas públicas para o desenvolvimento (Arretche, 1999). Da mesma forma, o compromisso dos beneficiados, dos diferentes grupos de interesse, terceiro setor, autoridades legislativas e executivas é fundamental para que a implementação de ações se efetive e tenha sustentabilidade (Acselrad e Leroy, 1999). A participação da sociedade civil na gestão de políticas públicas é um elemento para a efetividade e, sobretudo, de democratização do poder local. Desse modo:

[A democracia] deve pressupor que os cidadãos não sejam apenas aqueles de quem se fala, [o caráter normativo das políticas], mas também aqueles a quem se fala e, se possível, embora isso se mostre muito difícil, aqueles que falam (Ribeiro, 2000, p.15).

Nesse sentido, a avaliação de políticas públicas configura-se como um instrumento significativo para a verificação dos resultados de programas e políticas de desenvolvimento local, pois através dessas avaliações é que podemos mensurar os custos/benefícios e as causas e conseqüências da efetividade ou não das políticas, bem como o nível de organização societal dos diversos segmentos envolvidos e a sustentabilidade desses processos.

A avaliação de políticas públicas em âmbito local possibilita, por exemplo, a reflexão sobre qual padrão de desenvolvimento vem sendo implementado em determinada localidade ou município, a partir da obtenção de informações que indiquem quais os 
objetivos da política pública em questão; como vem sendo, ou foi implementada; quem é, e como vem sendo beneficiada a população-alvo dos programas e projetos públicos que ancoram o modelo de desenvolvimento em curso.

Esses critérios se diferenciam de autores para autores, dependendo de vários aspectos que norteiam o estudo realizado, como o momento da avaliação, que pode ser durante a execução ou ex-post, ou seja, quando da conclusão da implementação do programa ou parte dele, sendo uma avaliação que acompanha a implementação ou execução do programa.

A tradução literal da expressão ex-post facto é "a partir do fato passado". Isso significa que esse tipo de avaliação ou pesquisa dá-se após a ocorrência do programa ou parte dele. O desafio para o pesquisador, nesse tipo de estudo, é reconstituir e identificar situações que se desenvolveram e trabalhar sobre elas como se estivessem submetidas a controles e análises em tempo real, ou seja, vivenciando o processo de implementação.

Para muitos autores, o estudo de avaliação de políticas públicas deve considerar os desafios e possibilidades de operacionalização de uma metodologia de avaliação que leve em conta a natureza do programa e os meios disponíveis. Dessa forma, a importância de avaliar está na possibilidade de uma maior eqüidade e sustentabilidade, ou seja, garantir a capacidade de continuidade dos efeitos benéficos dos programas, permitindo uma distribuição de maneira justa, compatível e tornando mais sensato e efetivo os gastos públicos e ações de políticas diante das pressões sobre o Estado.

Arretche (1999) faz distinção entre avaliação política; avaliação de uma dada política pública; e, análise de políticas públicas, concordando que cada uma das distintas abordagens avaliativas mencionadas supõe distintos instrumentos de operação e, por conseqüência, abordagens e conclusões de diferente natureza.

Para essa autora, a avaliação política concentra-se na análise e elucidação do critério ou critérios que fundamentam determinada política: as razões que a tornam preferível a qualquer outra; a avaliação de uma dada política pública procura atribuir uma relação de causalidade entre um programa x e um resultado y, ou ainda, que na ausência do programa $\mathrm{x}$, não teríamos o resultado $\mathrm{y}$; finalmente, na análise de políticas públicas, dedica-se ao exame da engenharia institucional e dos traços constitutivos dos programas.

Ainda segundo Arretche (1999), nos últimos anos vêm se sofisticando os mecanismos de avaliação da eficiência em políticas e programas públicos. Em primeiro lugar, porque a escassez de recursos públicos exige maior racionalidade de planejamento dos gastos; e em segundo, pelas demandas sociais. Outra variável que se deve considerar é da apropriação de recursos públicos e a sua captação. A gestão dos mesmos traduz por um lado o processo de racionalização dos recursos públicos e o nível de democratização dessas gestões, agregando a participação da população. Afinal, vivemos uma época na qual o controle social é palavra-chave no processo de confiança pública. Daí:

... a probidade, competência e eficiência no uso de recursos publicamente apropriados constituem, em regimes democráticos, uma das condições para a confiança pública (public confident) no Estado e nas instituições democráticas. $O$ desperdício de recursos, 
a corrupção ou a incapacidade governamental são, na verdade, entraves à utilização de recursos publicamente geridos para finalidades efetivamente públicas (Cohen e Rogers, 1993, p. 40 apud Arretche, 1999, p.36).

Esse tipo de constatação assinala que as avaliações de políticas públicas, realizadas por pesquisadores acadêmicos e instituições de pesquisa são peças fundamentais para examinar os pressupostos e fundamentos políticos de uma determinada política pública. Na prática, a adoção de métodos e critérios de avaliação nos permite estabelecer uma dimensão de causalidade entre os objetivos das políticas e programas e os seus resultados, possibilitando uma gestão local mais eficiente do ponto de vista do gasto público e do impacto social.

Para Arretche (1999), é possível distinguir três critérios de avaliação de políticas públicas: eficácia, eficiência e efetividade. Outros autores preferem usar o critério de impacto ao invés da efetividade; todavia, podemos entender que ambos têm a pretensão de avaliar a dimensão dos resultados sociais de uma política pública.

A eficácia está direcionada às metas, ou seja, a eficácia de uma política dá-se na possibilidade efetiva de atingir uma quantidade satisfatória de suas metas, isto é, metas previstas e metas alcançadas. Sobre esse critério, escreve Figueiredo \& Figueiredo, 1986 (apud Arretche, 1999, p.34): Por avaliação de eficácia entende-se a avaliação da relação entre os objetivos e instrumentos explicitados de um dado programa e seus resultados efetivos.

A principal crítica à avaliação de eficácia está no apontamento metodológico e nas equações utilizadas pelos pesquisadores para avaliar a causalidade (comparativa) entre as metas propostas e as metas alcançadas; pois, em muitas avaliações existem exames fictícios e de confiabilidade questionável, seja pelo não acesso aos dados, carências de planos de trabalho e projetos que apontem os objetivos de uma determinada política a ser implementada e, conseqüentemente, as metas alcançadas, seja na processualidade das ações de implementação, execução e, sobretudo, na carência de diagnósticos ex-ante realizados ao começar a implementação, antecipando fatores considerados no processo decisório (número de beneficiados, situação econômica, perfil da população, etc).

Na avaliação de eficiência, escreve Figueiredo \& Figueiredo (1986 apud Arretche, 1999, p. 34): por avaliação de eficiência, entende-se a avaliação da relação entre o esforço empregado na implementação de uma dada política e os resultados alcançados.

A literatura relativa à avaliação de políticas públicas permite concentrar tipos de avaliação, considerando os aspectos que serão objetos de estudo, isto é, a gênese, o diagnóstico, a formulação e a implementação da política. As avaliações podem ser de processo, incluindo a cobertura, a implementação e o ambiente organizacional em que se desenvolve a política; e de eficácia, eficiência e efetividade, compreendendo os produtos, os efeitos, os meios e os resultados previstos e não previstos da política. De acordo com Figueredo \& Figueredo (apud Arretche, 1999, p.31): por efetividade, entende-se o exame da relação entre a implementação de um determinado programa e seus impactos e/ou resultados, isto é, seu sucesso ou fracasso em termos de uma efetiva mudança nas condições sociais prévias da vida das populações atingidas pelo programa. 
A efetividade de uma política pública está ligada à relação dos objetivos de sua implementação e aos resultados. De fato, constatamos a efetividade de uma dada política pública quando ela atinge os objetivos definidos em sua implementação e os seus impactos e/ou resultados, ou seja, seu sucesso ou fracasso, em termos de uma efetiva mudança nas condições sociais da vida das populações atingidas pelo programa (Arretche, 1999).

\section{Á guisa de conclusão}

No Brasil, os estudos relacionados com a temática das políticas públicas ainda não constituiu uma tradição no que se refere à avaliação. A crescente necessidade de realizar a avaliação de políticas públicas pode ser um fator impulsionador para a consolidação desta tradição.

Assim, a avaliação de políticas públicas em âmbito local possibilita, por exemplo, a reflexão sobre qual padrão de desenvolvimento vem sendo implementado em determinada localidade ou município, a partir da obtenção de informações que indiquem quais os objetivos da política pública em questão; como vem sendo, ou foi implementada; quem é, e como vem sendo beneficiada a população-alvo dos programas e projetos públicos que ancoram o modelo de desenvolvimento em curso.

Portanto, o desafio desse momento é o da implementação de metodologias capazes de garantir a eqüidade e sustentabilidade do desenvolvimento, a partir da capacidade de continuidade dos efeitos benéficos dos programas e políticas, permitindo também, uma distribuição de maneira justa, compatível e tornando mais sensato e efetivo os gastos públicos. E a participação de diversos atores sociais é uma condição essencial, pois como diz um provérbio africano: nós não herdamos o mundo dos nossos pais, mas tomamos emprestado dos nossos filhos. Isto significa dizer, que além da participação, temos o desafio de sair da esfera do discurso para sermos mais pragmáticos, no sentido da implementação de metodologias capazes de possibilitarem o alcance de resultados desejados e que esses resultados sejam aqueles desejados por todas as sociedades presentes e futuras.

\section{Referências Bibliográficas:}

ACSELRAD, Henri e LEROY, Jean-Pierre. Novas premissas da sustentabilidade democrática. Cadernos de debate Brasil Sustentável e Democrático, n. 1. Rio de Janeiro: FASE, P. 11-47, 1999.

ARRETCHE, Marta T. S. Tendências no estudo sobre avaliação. In: RICO, Elizabete Melo (org). São Paulo: Cortez/IEE, p.29-39, 1999.

BRÜSEKE, Franz Josef. O problema do desenvolvimento sustentável. In: CAVALCANTI, Clóvis. Desenvolvimento e natureza: estudos para uma sociedade sustentável. São Paulo: Cortez/Recife: FUNDAJ, p.29-40, 1995.

CARVALHO, Maria do Carmo Brand de. Avaliação participativa - uma escolha metodológica. In: RICO, Elizabete Melo (org). Avaliação de políticas sociais: uma questão em debate. São Paulo: Cortez/IEE, p. 87-94, 1999.

COSTA, Frederico Lustosa da e CASTANHAR, José Cezar. Avaliação de programas públicos: desafios conceituais e metodológicos. Rio de Janeiro: Revista Administração Pública. 37 (5): p. 969-992, set/out. de 2003. 
GUIMARÃES, Mauro. Educação ambiental e a gestão para a sustentabilidade. In: A contribuição da educação ambiental à esperança de Pandora. Santos, José Eduardo dos e Sato, Michèle (orgs). São Carlos - SP: Rima, p. 183-195, 2001.

HELENE, Maria Helena Marcondes e BICUDO, Marcelo Briza. Sociedades sustentáveis. São Paulo: Scipione,1994.

JACOBI, Pedro. Meio ambiente e sustentabilidade. In: O município no século XXI: cenários e perspectivas. Fundação Prefeito Faria Lima - CEPAM. Ed. Especial. São Paulo, p. 175-183, 1999.

NOSSA PRÓPRIA AGENDA. Comissão de Desenvolvimento e Meio Ambiente da América Latina e do Caribe. PNUD/BID. Brasília, 1984.

NOSSO FUTURO COMUM ou Relatório Brundtland. Comissão Mundial sobre Meio Ambiente e Desenvolvimento. Rio de Janeiro: Editora da Fundação Getúlio Vargas, 1991.

RIBEIRO, Renato Jeanine. A sociedade contra o social: o alto custo da vida pública no Brasil. São Paulo: Companhia das Letras, 2000, 233p.

SACHS, Ignacy. Estratégias de transição para o século XXI: desenvolvimento e meio ambiente. São Paulo. Studio Nobel/Fundap, 1993.

SANDER, Benno. Administração de educação no Brasil: é hora da relevância. Brasília: Educação Brasileira - Revista do Conselho de Reitores das Universidades Brasileiras CRUB. Ano IV . N 9. p. 8-27. $2^{\circ}$ semestre de 1982. 